\title{
A RELAÇÃO ENTRE CAPITAL SOCIAL E CONSUMO SOLIDÁRIO: UMA EXPERIÊNCIA DE FEIRA VIRTUAL
}

\author{
The Relationship Between Social Capital and Solidary Consumption: A Virtual Fair Experience
}

\section{RESUMO}

O presente estudo buscou aproximar os princípios da economia solidária à ideia de capital social, objetivando mensurar os níveis de capital social na associação de consumidores da rede Bem da Terra, em Pelotas/RS. A rede Bem da Terra foi criada para congregar produtores agrícolas familiares, empreendedores urbanos e consumidores para fins de alavancar um projeto de comércio justo. Neste contexto, o presente artigo investiga se elementos do capital social estão presentes entre os consumidores da feira e se este ativo tem contribuído para a sustentabilidade econômica da feira; também, quer-se avaliar se os consumidores ativos da feira diferem dos inativos em termos de capital social. Para atingir tais objetivos, adotou-se uma metodologia quantitativa, através da realização de um survey com posterior análise estatística para dimensionar as diferentes facetas do capital social presente. Como principais conclusões destaca-se que (01) o nível de capital social existente no grupo de consumo pode ser considerado suficiente para garantir o funcionamento da feira virtual; (02) nem todas as dimensões teóricas do capital social estão presentes no grupo de consumidores; e (03) os consumidores ativos da feira virtual possuem maior nível de capital social do que aqueles que deixaram de participar do projeto. Como contribuição significativa, o estudo destaca a relevância da confiança e do trabalho coletivo como sustentação econômica de empreendimentos solidário.

Retiele Vellar

Universidade Federal de Pelotas

retielevellar@hotmail.com

Mário Duarte Canever

Universidade Federal de Pelotas

canever@ufpel.edu.br

Lúcio André Fernandes

Universidade Federal de Pelotas

lucio.fernandes@ufpel.edu.br

Décio Cotrim

Universidade Federal de Pelotas

deciocotrim@yahoo.com.br

Recebido em: 31/03/2020. Aprovado em: 13/11/2020.

Avaliado pelo sistema double blind review

Avaliador científico: Eduardo César Silva

DOI: $10.48142 / 2220201618$

\begin{abstract}
The present study related solidarity economy principles to the idea of social capital, aiming to measure social capital levels in Bem da Terra consumers' association, in Pelotas/RS. The Bem da Terra network was created to bring together family farmers, urban entrepreneurs and consumers to leverage a project for fair trade purposes. This article investigates whether elements of social capital are present among consumers at the fair and whether this asset has contributed to economic sustainability of the fair. We also want to assess whether active consumers at the fair differ from inactive ones in terms of social capital. To achieve these objectives, a quantitative methodology was adopted, by conducting a survey with subsequent statistical analysis to measure different facets of social capital. As main conclusions it is highlighted that (01) social capital level existing in the consumption group can be considered sufficient to guarantee virtual fair functioning; (02) not all theoretical dimensions of social capital are present in the consumer group; and (03) virtual fair active consumers have a higher social capital level than those who no longer participate in the project. As a significant contribution, the study highlights the relevance of trust and collective work as an economic support for solidarity enterprises.
\end{abstract}

Palavras-chave: Consumidores; Comércio Justo; Economia Solidária; Projeto Social.

Keywords: Consumers; Fair Trade; Solidary Economy; Social Project.

Organizações Rurais \& Agroindustriais, Lavras, 22:e1618, 2020 


\section{INTRODUÇÃO}

O capital social é tema recorrente nas pesquisas sobre desenvolvimento de territórios e comunidades, especialmente nos campos da sociologia e da teoria gerencial. Estudos empíricos enfocam os efeitos do capital social em diversas medidas de desempenho em nível organizacional, como os apresentados por Yiu e Lau (2008), Casciaro e Lobo (2015), Fonti e Maoret (2016), e ao nível individual por Xiao e Tsui (2007) e Hador (2016). Alto nível de capital social é considerado um fator crítico para a criação de conhecimento (HAU et al., 2013; YEN et al., 2015) e para se ter altos níveis de criatividade e soluções inovadoras (CHEN et al., 2008; HU; RANDEl, 2014) nas organizações e instituições.

O conceito de capital social foi discutido primeiramente nos trabalhos de Bourdieu (1986) e Coleman (1988), os quais estudaram os laços entre indivíduos, famílias, instituições, comunidades ou grupos como forma de construir caminhos para o fortalecimento da sociedade civil e para o desenvolvimento humano. $\mathrm{Na}$ perspectiva gerencial, autores como Nahapiet e Ghoshal (1998) foram pioneiros e definem o capital social como elemento central para a construção de redes de colaboração e para o compartilhamento de recursos (FORMIGA et al., 2019). Este artigo fará uso destes conceitos para avaliar o capital social presente em um projeto de economia solidária.

A economia solidária tem sido uma alternativa de organização associativa do trabalho e suas relações de produção em busca de novas estratégias de inclusão social (IPEA, 2016). No Brasil, inúmeras publicações destacam o papel da economia solidária como forma de geração de trabalho e renda de forma coletiva, em contraponto às formas tradicionais de organizar as atividades econômicas no sistema capitalista (SANTOS et al., 2013; MAIA, 2014; CRUZ, 2014; IPEA, 2016; BALTHAZAR; CARDOSO, 2017; RIBEIRO; OLIVEIRA, 2017; OLIVEIRA, 2018; SILVA et al., 2018).

Assim este artigo desenvolve-se a partir de uma análise do capital social em uma experiência de economia solidária realizada no Grupo de Consumidores Responsáveis (GCR) vinculado a um projeto cooperativo (Associação Bem da Terra) que envolve consumidores e agricultores familiares localizados na região Sul do estado do Rio Grande do Sul. O GCR Bem da Terra tem seis anos de funcionamento e, embora no início houvesse grande engajamento de consumidores para a compra virtual de alimentos orgânicos (agroecológicos) produzidos pelos agricultores, com o passar do tempo houve forte rodízio de consumidores e muitos desligamentos.

A economia solidária enfatiza integração de grupos com comprometimento social de forma que resulte em conquistas para todos os envolvidos (GAIGER; GRUPO ECOSOL, 2014). Neste sentido, o capital social presente no grupo tenderia a sustentar a cooperação e a solidariedade, conferindo benefícios através de altos níveis de comprometimento social e relações baseadas em confiança, capazes de propiciar novos formatos produtivos e novos hábitos de consumo.

Seguindo Coleman (1988) e Putnam (1996), assume-se que o capital social não se localiza nos indivíduos, mas nas relações entre eles. Assim, a existência de capital social aumenta os recursos à disposição dos indivíduos que se encontram imersos no projeto da feira virtual Bem da Terra. O capital social presente pode ser caracterizado como um atributo do projeto conferindo-lhe valor não tangível, mas altamente valioso no contexto econômico. $\mathrm{O}$ artigo visa a mensurar os níveis de capital social na associação de consumidores da rede Bem da Terra, verificando se os elementos do capital social estão presentes no contexto do estudo e se contribuem para a sustentabilidade econômica da feira virtual do projeto Bem da Terra. Para tal, utilizar-se-á um instrumento, proposto por Onyx e Bullen (2000), para mensurar o capital social em comunidades ou grupos de pessoas participantes de organizações ou projetos como o caso em estudo. Secundariamente, investigar-se-á se o nível de capital social difere entre membros ativos e inativos da feira virtual.

O estudo evidencia a importância das novas formas de comercialização, produção e consumo e reconhece como a postura do consumidor, ao migrar de coadjuvante para protagonista, como na feira virtual mantida por um projeto de economia solidária, pode ser dependente de outros capitais, que não apenas o capital econômico tradicional. As pessoas, neste caso, consumidores, por meio de sua participação social em uma estrutura de comércio inovadora, podem contribuir com soluções que satisfazem tanto o consumidor como o produtor, e possibilitar a sustentabilidade econômica de empreendimentos da economia solidária.

\section{REFERENCIAL TEÓRICO}

Os inúmeros estudos acerca da teoria do capital social trazem, em suas bases, autores referências como Bourdieu (1980), Coleman (1988), Putnam (1996), 
Fukuyama (2000), Nahapiet e Ghoshal (1998), entre outros. Muitas são as definições de capital social que são apresentadas.

Bourdieu explica a existência do mundo social como se fosse "história acumulada" e diz que é impossível explicar a estrutura do funcionamento desse mundo sem que seja reintroduzida a noção do capital em todas as suas formas e não somente a reconhecida pela teoria econômica. Nesse sentido, o autor estabelece o "capital" como sendo o trabalho humano acumulado e identifica três tipos de capital: econômico, cultural e social (Bourdieu, 1986).

Esse capital social leva tempo para se acumular e está inscrito na objetividade das coisas na própria realidade desse mundo e pode ser propriedade do indivíduo, ou de um grupo, que mobiliza o conjunto de relações ou redes, conferindo muitos benefícios nos vários sentidos oriundos das relações de troca, assim como se observam os relacionamentos que existem entre famílias, escolas, associações etc. Todas as formas de capital social se reduzem a uma única, o capital econômico, porém, a aquisição de capital social requer deliberado investimento de recursos, tanto cultural quanto econômico, não havendo um processo específico para a conquista de capital social, pois cada lugar, rede, associação desenvolve uma dinâmica própria para desenvolvimento do mesmo (BOURDIEU, 1986).

Na década de 90, Putnam (1996) observou que regiões da Itália tinham níveis de desenvolvimento desigual associados aos estoques de capital social disponível em cada região. Para este autor, uma comunidade que apresenta um estoque abundante de capital social tende a ter mais facilidade para trabalhar em conjunto, pois, através da confiança adquirida nas relações, a cooperação é fomentada. Esta confiança que se estabelece não é cega, mas baseada na previsão de comportamento de um ator (entidade) dentro de um sistema mais complexo de relações como é uma comunidade, em que a confiança pessoal se transforma em confiança social (PUTNAM, 1996).

Assim como outras formas de capital, o capital social é produtivo, pois o produto gerado por relações grupais pautados na confiança, por exemplo, possivelmente é maior do que em grupos em que isto não ocorre. Nas comunidades cívicas, os estoques de capital social, como confiança, normas e sistemas de participação, criam círculos virtuosos que resultam em equilíbrios sociais com elevados níveis de cooperação, confiança e reciprocidade, civismo e bem-estar coletivo, tendendo a ser cumulativos e reforçar-se mutuamente, permitindo que essas regiões cresçam mais rápido do que as regiões com menos associações e mais hierarquia (PUTNAM, 1996).
Putnam (2000) propõe uma forma de medir capital social quantitativamente através de variáveis que incluem medidas de engajamento político (participação eleitoral, filiação a partidos políticos), aspectos da vida organizacional da comunidade (associações de pais e mestres, clubes, organizações cívicas em geral), medidas de voluntarismo comunitário (existência de entidades filantrópicas, serviços voluntários, entre outros), medidas de sociabilidade informal (número de visitas a amigos, ou número de horas que um indivíduo se entretém em casa, sozinho) e medidas de confiança social (percepção dos cidadãos quanto à honestidade e a confiança mútua).

Instrumentos para acessar o capital social foram propostos por vários autores em múltiplos contextos, como, por exemplo, no contexto acadêmico, por Alcázar et al. (2019); na área da saúde, por Souto et al. (2016); para mensurar o capital social de jovens envolvidos em organizações políticas por Valenzuela et al. (2020); para mensurar o capital social nas vizinhanças, Mohammadi et al. (2020); para mensurar o capital social no ambiente de trabalho, Formiga et al. (2019); entre outros. Cada um destes estudos empíricos obteve uma estrutura fatorial multidimensional do capital social, contemplando, em geral, de três a quatro fatores distintos. Os estudos mais tradicionais testaram uma estrutura fatorial do capital social seguindo a lógica teórica de Nahapiet e Ghoshal (1998), perfazendo uma dimensão relacional (confiança, normas e identificação social), uma cognitiva (compartilhamento de códigos, linguagem e narrativas) e uma estrutural (conexões e configuração da rede) (ALCÁZAR et al.; FORMIGA et al., 2019). Outros autores, no entanto, propuseram e obtiveram estruturas fatoriais muito diversas de acordo com o contexto do estudo, perfazendo fatores como confiança e colaboração (MOHAMMADI et al., 2020); habilidades pessoais e habilidades políticas (SOUTO et al., 2016); confiança social, confiança interpessoal, envolvimento social e solidariedade (VALENZUELA et al., 2020).

Pioneiros, Onyx e Bullen (2000) criaram um instrumento contendo 34 perguntas para mensurar capital social comunitário. Através da análise fatorial exploratória e confirmatória, obtiveram oitos dimensões que definem o capital social, as quais são: (i) participação na comunidade local; (ii) proatividade no contexto social; (iii) sentimentos de confiança e segurança; (iv) conexões com a vizinhança; (v) conexões com familiares e amigos; (vi) tolerância à diversidade; (vii) valor da vida; (viii) conexões no ambiente de trabalho (ONYX; BULLEN, 2000). 
Onyx e Bullen (2000) encontraram correlações positivas entre estes fatores, embora eles tenham também extraído fatores ortogonais: o primeiro fator se refere à participação das pessoas nas estruturas comunitárias formais, como em clubes, na coordenação de organizações locais, entre outras; o segundo fator diz respeito ao senso individual ou coletivo de se sentir capaz de agir no contexto social; o terceiro fator sumariza as questões relativas à confiança e aos sentimentos de segurança; o quarto fator se refere às relações informais que existem nas vizinhanças; o quinto trata das conexões mais íntimas existentes nas famílias e com amigos; o sexto fator se refere às compreensões de abertura à diversidade $\mathrm{e}$ tolerância; o sétimo fator se refere ao sentimento de pertencer e ser valorizado pela sociedade; finalmente, o oitavo fator se refere ao sentimento de pertencimento e identificação com as relações estabelecidas no ambiente de trabalho.

\section{METODOLOGIA}

O estudo de caso realizou-se no Grupo de Consumidores Responsáveis Bem da Terra, o qual está vinculado à Associação de Produtores Bem da Terra, localizada na região Sul do estado do Rio Grande do Sul. Este grupo de consumidores, juntamente com apoio de incubadoras da Universidade Católica de Pelotas (UCPel), da Universidade Federal de Pelotas (UFPel) e do Instituto Federal Sul-Riograndense de Pelotas (IFSul) dão sustentação à feira virtual Bem da Terra, fazendo sua gestão e um trabalho de extensão a produtores vinculados aos empreendimentos solidários da região.

Os Grupos de Consumo Responsáveis (GCRs) são iniciativas de pessoas organizadas que buscam acessar produtos alinhados com seus valores, preferencialmente alimentos saudáveis (entre outros itens) a preços acessíveis, produzidos por pequenos produtores. Usualmente, baseiam-se na autogestão e em diversas atuações voluntárias que não visam somente ao lucro, diferenciandose de lojas convencionais e empreendimentos comerciais (CALABRÓ, 2016).

A Rede Bem da Terra integra a produção (Associação de Produtores do Bem da Terra) ao consumo, por meio de feiras livres, uma banca no mercado público e a Feira Virtual, todas localizadas na cidade de Pelotas, região no extremo-sul do Estado do Rio Grande do Sul. O GCR do Bem da Terra originou-se conjuntamente com a Feira Virtual, no final de 2014, com a perspectiva de inserir pessoas que buscassem inicialmente produtos saudáveis, mas também abertos a ingressar numa organização com uma relação diferenciada entre a produção e o consumo. Atualmente, a Feira Virtual Bem da Terra oferta seus produtos através da plataforma virtual (www.cirandas.net), apresenta 213 consumidores organizados em 13 núcleos de consumo, abrangendo os municípios de Pelotas, Jaguarão e São Lourenço do Sul, e vem sendo um mecanismo de comercialização dos produtos de empreendimentos da economia solidária, para consumidores do GCR Bem da Terra. No entanto, para realização dos pedidos e vinculação aos núcleos de consumo é necessário "certo" comprometimento; o ponto inicial é a participação na acolhida, uma manhã de formação quando são explicados os princípios centrais da Feira (NESIC, 2019).

O universo de consumidores ativos e inativos da Feira Virtual totaliza 440 pessoas, aos quais foi solicitado para participarem da pesquisa via correio eletrônico (e-mail), em que se apresentou o estudo e a solicitação de preenchimento do mesmo. A coleta de dados para compor os elementos da amostra atende à seleção de forma aleatória, conforme orienta Yin (2010), e a mesma foi aplicada no período de abril e maio de 2019, estando o link para responder o questionário assim como seu armazenamento na plataforma digital Google Drive.

\subsection{Mensuração do capital social}

$\mathrm{O}$ instrumento utilizado neste artigo para mensurar o capital social em comunidades é uma adaptação do estudo desenvolvido primeiramente pelos pesquisadores australianos Onyx e Bullen (2000) e, posteriormente, utilizado por Macke et al. (2010), que traduziram e validaram o presente instrumento para o português. Os itens que compõem o instrumento de coleta de dados estão apresentados na (Tabela 1).

A escolha por utilizar este instrumento de Onyx e Bullen (2000) justifica-se: a) pelo instrumento já ter sido testado empiricamente em diferentes lugares e regiões; b) por sua construção ter sido embasada nas contribuições de Putnam e Colleman, cujos conceitos de capital social foram adotadas neste estudo; c) pelo fato do grupo de consumo responsável da rede Bem da Terra não se tratar de uma organização, que busca agregar valor por meio de seu capital social para obter vantagens competitivas diante de outras redes solidárias, mas por ser um grupo que consome e trabalha de forma conjunta, partilhando princípios e valores para garantir a sustentabilidade econômica da feira virtual 
e, consequentemente, beneficiar os empreendimentos de economia solidária da região de Pelotas/RS; e d) por reconhecer o conceito de comunidade não vinculado a uma demarcação espaço-geográfica definida, mas por ser um território-rede embasado em três princípios distintos referenciados sobre as vertentes: $1^{\circ}$ ) jurídico-políticas (centradas nas relações de poder-estado); $2^{\circ}$ ) simbólico cultural (valorizando em um grupo aspectos identitários e teias de significados); $3^{\circ}$ ) econômica (na perspectiva capitalista, com processos de produção e circulação de bens); todas atuando conjuntamente de forma complexa (HAESBAERT, 2003; 2004).

TABELA 1 - Quadro com os elementos constituintes dos fatores do capital social

\begin{tabular}{|c|c|}
\hline Fator & Variáveis \\
\hline \multirow{7}{*}{ Participação na Comunidade Local } & Participa de algum grupo na comunidade ou bairro como voluntário \\
\hline & Administra ou participa de um comitê de organização de algum grupo ou associação \\
\hline & Fez parte de um projeto na comunidade \\
\hline & Ajuda a organizar um novo serviço na comunidade \\
\hline & Participa em alguma ação da comunidade numa situação de emergência \\
\hline & É membro ativo de uma organização comunitária \\
\hline & Participa em eventos comunitários \\
\hline \multirow{7}{*}{ Proatividade no Contexto Social } & Tem iniciativa no ambiente de trabalho \\
\hline & Ajuda espontaneamente os colegas de trabalho \\
\hline & Sente liberdade para discordar da opinião da maioria \\
\hline & Busca resolver impasses de pessoas conhecidas \\
\hline & Tem acesso a informação para tomar decisões importantes \\
\hline & Sai da comunidade local para visitar a família \\
\hline & Recolhe o lixo deixado por outras pessoas \\
\hline \multirow{5}{*}{$\begin{array}{c}\text { Sentimentos de Confiança e } \\
\text { Segurança }\end{array}$} & Sente-se seguro na rua à noite \\
\hline & O lugar onde mora tem fama de ser um lugar seguro \\
\hline & Deixa que estranhos entrem em sua casa numa emergência \\
\hline & Acredita que a maioria das pessoas é confiável \\
\hline & Tem sentimento de lar com relação sua comunidade ou bairro \\
\hline \multirow{5}{*}{ Vínculos de Vizinhança } & Visita os vizinhos \\
\hline & Ajuda um vizinho doente \\
\hline & Pede a um vizinho que cuide de seus filhos \\
\hline & Ao sair de casa, aproveita para visitar vizinhos e amigos \\
\hline & Recebe ajuda de amigos quando precisa \\
\hline \multirow{3}{*}{ Vínculos de Família e Amizade } & Sai para almoçar/jantar com outras pessoas fora da sua família \\
\hline & Telefona para os amigos \\
\hline & Conversa com muitas pessoas \\
\hline \multirow{2}{*}{ Tolerância à Diversidade } & Acredita que o multiculturalismo é saudável \\
\hline & Aprecia diferentes estilos de vida \\
\hline \multirow{2}{*}{ Valor a Vida } & Sente-se valorizado pela sociedade \\
\hline & Sente-se satisfeito com a vida \\
\hline \multirow{3}{*}{ Vínculos com o Trabalho } & Sente-se parte de uma equipe de trabalho \\
\hline & Considera colegas de trabalho também como amigos \\
\hline & Sente-se parte da comunidade ou local onde trabalha \\
\hline
\end{tabular}

Fonte: Adaptado de (ONYX; BULLEN, 2000, p. 40- 41) 
Portanto, a versão do instrumento de coleta de dados utilizado no presente estudo seguiu o modelo de Onyx e Bullen (2000), e Macke et al. (2010), aplicado ao contexto da associação de consumidores responsáveis da Feira Virtual Bem da Terra, seguindo os procedimentos de validação, sendo encaminhado para especialistas da área conforme recomenda Yin (2010). Conforme observações apresentadas por Hair et al. (2009) e Field (2009), este estudo considera uma amostra de cem respondentes adequada para se obter confiabilidade das análises, desde que atenda aos níveis mínimos estabelecidos pelas comunalidades e o teste KMO (Kaiser-Meyer-Olkin).

A coleta de dados destinou-se ao grupo de consumidores ativos e inativos da associação de consumidores responsáveis Rede Bem da Terra, o instrumento de coleta é organizado em duas seções: a) primeira: composta por 14 questões que registram informações sobre o perfil do respondente; b) segunda: composta por 34 questões fechadas, as quais estão organizadas em oito fatores que compõem os elementos do capital social. As variáveis que integram os fatores são medidas através de uma escala de concordância de 4 pontos ( $1=$ não, nunca e $4=\operatorname{sim}$, sempre), conforme utilizado no instrumento de Onyx e Bullen (2000), visto que esse tipo de escala se destina a medir a frequência com que determinada atividade é realizada, sendo essa a essência do que se busca medir no capital social associativo.

As variáveis estão alocadas nos oito fatores do capital social, segundo Onyx e Bullen (2000), já apresentados anteriormente neste artigo. A mensuração do capital social ocorre através da observação das médias das variáveis, realizada a partir das respostas, e com as médias individuais de cada variável é realizado o cálculo para a média do fator. A extração dos fatores (análise fatorial) foi realizada através do software Statistical Package for the Social Sciences (SPSS), versão 21, por meio do método análise de componentes principais (Principal Component Analysis), com rotação varimax e tratamento listwaise.

Por último, o estudo de caso contemplou uma análise qualitativa através de entrevistas abertas destinadas ao grupo de consumidores inativos da Feira Virtual. Esta etapa teve como propósito compreender melhor a relação dos membros ativos e inativos da feira com o capital social. As entrevistas foram realizadas presencialmente, com uma breve conversa inicial e apenas uma questão central: "Por qual ou quais motivos você parou de consumir na Feira Virtual?" Todas as entrevistas foram registradas na forma de áudio, com a gravação autorizada pelo entrevistado e disponibilizadas em arquivo digital, sendo que o fechamento do número de entrevistados ocorreu por saturação teórica dos dados (FONTANELLA et al., 2011).

\section{RESULTADOS E DISCUSSÃO}

\subsection{Análise descritiva}

A amostra investigada soma 108 respondentes, sendo que dois foram excluídos por omissão de dados, resultando em 106 respondentes ativos ou inativos da associação de consumidores da Feira Virtual, que soma 440 consumidores associados. Deste total, 213 são consumidores ativos e 227 consumidores inativos. Dos 106 respondentes, $63,9 \%$ eram consumidores ativos e $36,1 \%$ inativos, sendo inativos os associados que não realizavam compras por mais de 3 meses seguidos na Feira.

Como características gerais da amostra, salientase que os respondentes eram majoritariamente da cidade de Pelotas $(75,9 \%)$, com maior participação do gênero feminino $(64,8 \%)$, e com predomínio de pessoas que atualmente tinham atividade remunerada (81,5\%). A idade média dos respondentes era próxima aos 41 anos, sendo a idade mínima de 20 e a máxima de 71 anos, os quais apresentavam um elevado nível de instrução, sendo que $59,2 \%$ dos respondentes apresentavam formação em nível de pós-graduação e renda predominante de até seis salários mínimos (Tabela 2).

Destaca-se, também, que, do total de respondentes, 47,2\% eram casados ou possuíam união estável e 56,5\% possuíam filhos, mas apenas $16,7 \%$ destes têm filhos menores de 10 anos de idade.

Entre os consumidores ativos da feira virtual, havia forte prevalência de respondentes participantes de partidos políticos, enquanto entre os inativos esta prevalência não era observada no mesmo nível (significância do teste de Qui-quadrado de Pearson - $\mathrm{p}<0,01$ ). Tal resultado evidencia uma associação positiva entre ser membro (participar) de partido político e o engajamento na feira virtual.

Observou-se também que ser consumidor ativo da feira virtual estava associado significativamente a ser membro de sindicatos e associações vinculadas ao trabalho. Mais de $65 \%$ dos respondentes ativos da feira eram vinculados a estas instituições, enquanto entre os inativos apenas $35,9 \%$ participavam de sindicatos e associações $(p<0,01)$. Destaca-se, também, a 
associação significativa entre ser consumidor ativo e os motivos da participação na feira. Identifica-se que quem era ativo estava muito mais motivado por apresentar afinidades com a economia solidária e, também, por buscar uma forma de consumo mais sustentável do que os inativos $(p<0,01)$. Por outro lado, percebe-se que os consumidores inativos eram mais motivados por outras razões, como a busca por um alimento saudável ou pela oportunidade de comprar diretamente do produtor. Tal distinção caracteriza claramente que os consumidores ativos/inativos são motivados por razões diferentes, ou seja, aqueles que se mantêm ativos estão mais propensos a valores altruístas e pelo bem da coletividade, enquanto os inativos são mais influenciados pela satisfação de valores individuais, como a preservação da própria saúde.

TABELA 2 - Dados descritivos dos consumidores respondentes ativos e inativos da Feira Virtual

\begin{tabular}{|c|c|c|c|c|}
\hline \multirow{2}{*}{ Variáveis } & \multicolumn{3}{|c|}{ Respondentes (\%) } & \multirow{2}{*}{$\begin{array}{l}\text { Qui-Quadrado } \\
\text { (p valor) }\end{array}$} \\
\hline & Inativo & Ativo & Total & \\
\hline \multicolumn{5}{|c|}{ Gênero } \\
\hline Feminino & 61,5 & 66,7 & 64,8 & \multirow{2}{*}{.592} \\
\hline Masculino & 38,5 & 33,3 & 35,2 & \\
\hline \multicolumn{5}{|c|}{ Renda } \\
\hline Até seis salários-mínimos (R\$998,00) & 59,0 & 59,4 & 59,3 & \multirow{2}{*}{.075} \\
\hline Acima de seis salários-mínimos $(\mathrm{R} \$ 998,00)$ & 41,0 & 40,5 & 40,7 & \\
\hline \multicolumn{5}{|c|}{ Grau de Instrução } \\
\hline Até Graduação & 43,6 & 39,1 & 40,8 & \multirow{2}{*}{.258} \\
\hline Pós-Graduação & 56,4 & 60,9 & 59,2 & \\
\hline \multicolumn{5}{|c|}{ Possui Filhos } \\
\hline $\operatorname{Sim}$ & 43,6 & 63,8 & 56,5 & \multirow{2}{*}{.105} \\
\hline Não & 56,4 & 36,2 & 43,5 & \\
\hline \multicolumn{5}{|c|}{ Filiado ou participa de partido político } \\
\hline $\operatorname{Sim}$ & 15,4 & 53,6 & 39,8 & \multirow{2}{*}{.000} \\
\hline Não & 84,6 & 46,4 & 60,2 & \\
\hline \multicolumn{5}{|c|}{ Membro ou participa de religião } \\
\hline Sim & 20,5 & 20,3 & 20,4 & \multirow{2}{*}{.978} \\
\hline Não & 79,5 & 79,7 & 79,6 & \\
\hline \multicolumn{5}{|c|}{ Membro ou Participa de Sindicato ou Associação } \\
\hline Sim & 35,9 & 65,2 & 54,7 & \multirow{2}{*}{.003} \\
\hline Não & 64,1 & 34,8 & 45,3 & \\
\hline \multicolumn{5}{|c|}{ Municípios de Abrangência } \\
\hline Pelotas & 79,3 & 73,9 & 75,9 & \multirow{4}{*}{.005} \\
\hline Jaguarão & 0,0 & 14,5 & 9,3 & \\
\hline São Lourenço & 2,6 & 10,1 & 7,4 & \\
\hline Outros & 18,1 & 1,5 & 7,4 & \\
\hline \multicolumn{5}{|c|}{ Motivo da Participação } \\
\hline Economia Solidária & 23,1 & 49,4 & 39,8 & \\
\hline Consumo Sustentável & 23,1 & 30,4 & 27,8 & \\
\hline Alimentação Saudável & 25,6 & 13,0 & 17,6 & .003 \\
\hline Compras direto da produção & 17,9 & 5,8 & 10,2 & \\
\hline Outros & 10,3 & 1,4 & 4,6 & \\
\hline
\end{tabular}

Fonte: Elaborado pelo Autor 


\subsection{Capital Social e consumidores da feira}

Os resultados dos testes de adequabilidade da amostra da análise fatorial foram satisfatórios, em vista de que o teste $\operatorname{KMO}(0,804)(<0,05)$ mostra que a realização da análise fatorial é possível, e o teste de Bartlett foi significativo a $\mathrm{p}<0,001$, indicando que existem correlações suficientes entre as variáveis, estando de acordo com os pré-requisitos para seguir a análise fatorial conforme Hair et al. (2009). A medida de confiabilidade do alfa de Cronbach $(0,913)$ mostra que a escala utilizada no questionário, para a obtenção das respostas, foi adequada, pois, conforme orienta Malhotra (2001), se recomendam valores de alfa superiores a 0,60 .

A análise fatorial convergiu em um total de 11 interações, resultando em 8 fatores, considerando o critério de autovalor maior que a unidade (Tabela 3). Foram eliminadas cinco variáveis (Q8, Q11, Q12, Q17 e Q20)1, pois apresentaram cargas fatoriais muito baixas, $<0,4$, resultando em 29 variáveis organizadas nos oito fatores. Juntos os oito fatores explicam mais de $68 \%$ da variância nos dados, sendo o primeiro fator sozinho responsável por quase um terço do total, ou seja, do nível de capital social existente no grupo envolvido no projeto.

Os dados concernentes aos fatores resultantes da análise fatorial estão expostos na (Tabela 4), junto as suas cargas fatoriais e comunalidades. Também, foram calculados os alfas de Cronbach para os oitos fatores, a

${ }^{1} Q 8$ - Você alguma vez recolheu lixo de outras pessoas em local público? Q11 - Se você discorda da "opinião da maioria", você se sente à vontade (livre) para expressar opinião em contrário?

Q12 - Se você se desentende com um vizinho "por qualquer motivo", você se esforça para mediar ("resolver de forma pacífica e consensual") a situação? Q17 - Se o veículo de alguém estraga em frente a sua casa, você oferece o seu telefone pessoal/residencial ao motorista com o objetivo de ajudá-lo? $\mathrm{Q} 20$ - Você recebe ajuda de amigos quando precisa? média de cada uma das variáveis (agrupadas em cada um dos oito fatores) e a média geral do fator.

Conforme a Tabela 4, é possível observar que os fatores encontrados neste estudo se diferem ligeiramente dos apresentados por Onyx e Bullen (2000). O primeiro fator resultante da análise fatorial é muito significativo e lembra a veia Putniana do conceito de capital social, ao aglutinar a ideia de recursos, que acrescenta benefícios coletivos assim como benefícios pessoais, visto que a pessoa que realiza o investimento também colhe benefícios. Percebe-se que, por meio do resultado das escolhas pessoais, na busca de uma alimentação mais saudável, uma forma de consumo mais sustentável, assim como uma economia mais solidária, configura-se um conjunto de valores comuns do grupo de consumidores/ ex-consumidores do projeto Bem da Terra. Isso possibilita o desenvolvimento de conexões, identidade e cooperação resultando em um sentimento de pertencimento e responsabilidade; ademais, confere bem estar e satisfação pessoal, possibilitando que esse fator possa ser nomeado como "Identificação social e satisfação pela vida".

Neste fator destacam-se as médias das variáveis Q31 (Sente-se satisfeito com a vida), Q26 (Conversa com muitas pessoas) e Q34 (Você se sente parte de uma "equipe de trabalho"), as quais expressam o sentimento de bem estar, de "lar" e de amizade ao participarem da comunidade e do ambiente de trabalho, dois bons indicadores de capital social com potencial de influenciarem as pessoas a participarem de trabalho voluntário e de projetos solidários, como é o caso da feira de consumo virtual Bem da Terra.

O segundo fator extraído dos dados denominamos "Participação na Comunidade Local", que resultou bastante similar ao primeiro fator proposto por Onyx e Bullen (2000), com exceção apenas da variável Q7 que,

TABELA 3 - Número de fatores obtidos, autovalores e suas variâncias

\begin{tabular}{cccc}
\hline Fatores & Autovalor & Variância Explicada pelo fator (\%) & Somatório da Variância Explicada (\%) \\
\hline 1 & 8,291 & 28,589 & 28,589 \\
2 & 2,661 & 9,176 & 37,765 \\
3 & 2,223 & 7,664 & 45,429 \\
4 & 1,598 & 5,511 & 50,939 \\
5 & 1,433 & 4,941 & 55,881 \\
6 & 1,272 & 4,386 & 60,267 \\
7 & 1,195 & 4,120 & 64,387 \\
8 & 1,052 & 3,627 & 68,014 \\
\hline
\end{tabular}

Fonte: Resultados gerados a partir da Pesquisa

Organizações Rurais \& Agroindustriais, Lavras, 22:e1618, 2020 
no nosso estudo, foi eliminada por não apresentar carga fatorial adequada. $\mathrm{O}$ fator resultante é considerado muito importante para analisar o capital social, seus elementos identificam a participação social e, neste estudo, não apresentou um peso conceitual tão forte como nos estudos de Onyx e Bullen (2000), mas teve uma média $(2,006)$ que não pode ser considerada baixa. Pelos dados pode-se compreender que as pessoas do grupo de consumo na feira não são tão atuantes nos bairros/ comunidades ondem residem, como o são na feira (rede social). Este achado reforça a abordagem de território apresentada por Haesbaert $(2003 ; 2004)$, utilizada neste estudo, evidenciando que o capital social se reconfigura em grandes centros urbanos, ultrapassando as fronteiras espaço geográficas de um bairro ou centro comunitário, mas desenvolvendo-se por meio de uma rede de valores e aspectos identitários, assim como os processos de produção e circulação de mercadorias e bens.

TABELA 4 - Estrutura dimensional do capital social entre os consumidores da feira virtual

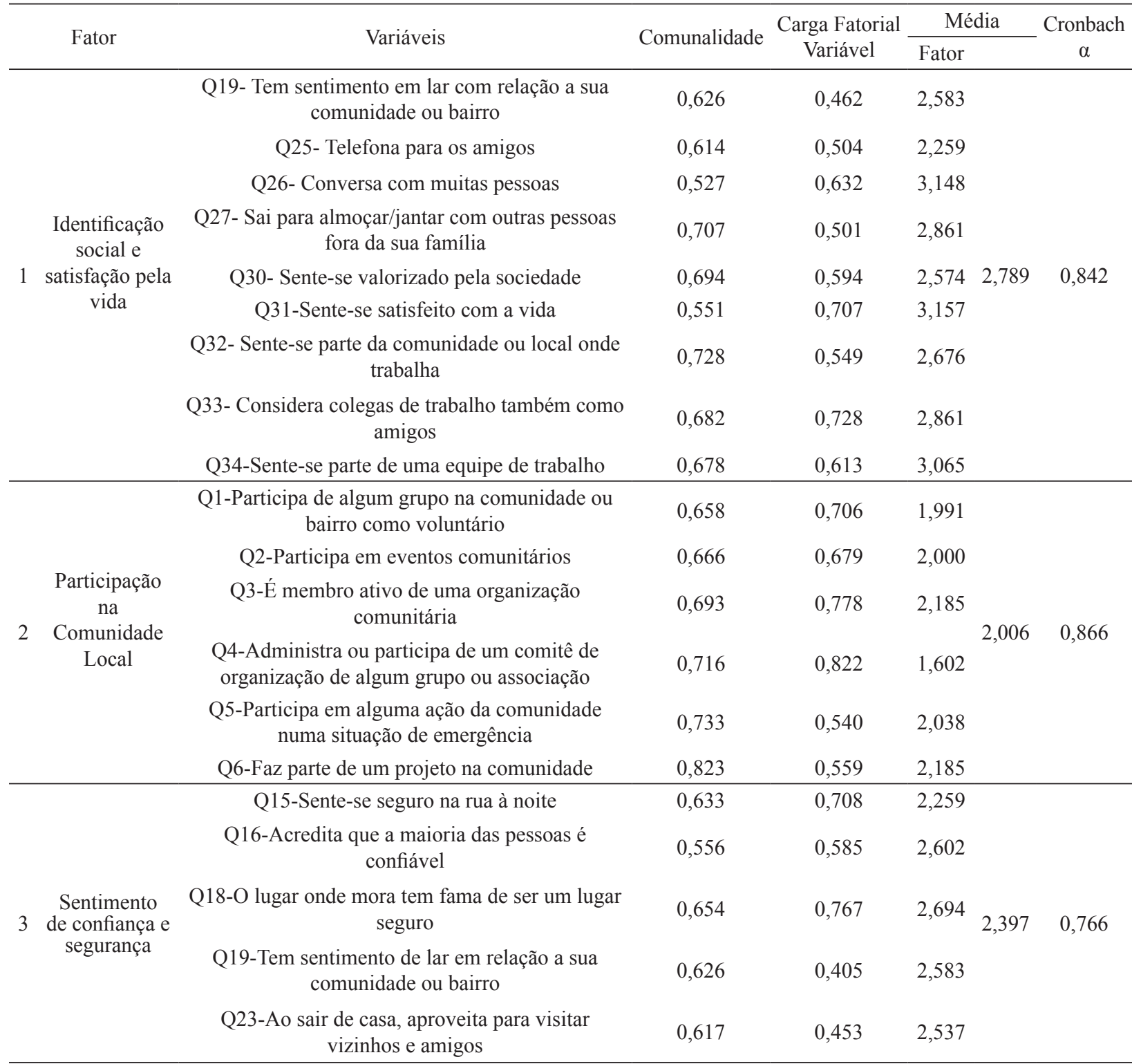


TABELA 4 - Continuação

\begin{tabular}{|c|c|c|c|c|c|c|c|}
\hline & \multirow{2}{*}{ Fator } & \multirow{2}{*}{ Variáveis } & \multirow{2}{*}{ Comunalidade } & \multirow{2}{*}{$\begin{array}{l}\text { Carga Fatorial } \\
\text { Variável }\end{array}$} & \multicolumn{2}{|c|}{ Média } & \multirow{2}{*}{$\begin{array}{c}\text { Cronbach } \\
\alpha\end{array}$} \\
\hline & & & & & Fator & & \\
\hline \multirow{4}{*}{4} & \multirow{4}{*}{$\begin{array}{l}\text { Vínculos com } \\
\text { a vizinhança }\end{array}$} & Q21-Pede a um vizinho que cuide de seus filhos & 0,568 & 0,644 & 1,870 & \multirow{4}{*}{2,000} & \multirow{4}{*}{0,715} \\
\hline & & Q22-Visita os vizinhos & 0,672 & 0,727 & 1,870 & & \\
\hline & & Q24-Ajuda um vizinho doente & 0,732 & 0,741 & 2,000 & & \\
\hline & & Q25-Telefona para os amigos & 0,614 & 0,482 & 2,259 & & \\
\hline \multirow[b]{2}{*}{5} & \multirow{2}{*}{$\begin{array}{l}\text { Proatividade } \\
\text { no contexto de } \\
\text { trabalho }\end{array}$} & Q13-Tem iniciativa no ambiente de trabalho & 0,770 & 0,788 & 3,593 & \multirow[b]{2}{*}{3,537} & \multirow[b]{2}{*}{0,861} \\
\hline & & $\begin{array}{l}\text { Q14-Ajuda espontaneamente os colegas de } \\
\text { trabalho }\end{array}$ & 0,842 & 0,858 & 3,481 & & \\
\hline \multirow{3}{*}{6} & \multirow{3}{*}{$\begin{array}{l}\text { Envolvimento } \\
\text { comunitário }\end{array}$} & $\begin{array}{l}\text { Q5-Participa em alguma ação da comunidade } \\
\text { numa situação de emergência }\end{array}$ & 0,733 & 0,574 & 2,038 & \multirow{3}{*}{2,025} & \multirow{3}{*}{0,804} \\
\hline & & Q6-Toma parte de um projeto na comunidade & 0,823 & 0,629 & 2,185 & & \\
\hline & & $\begin{array}{l}\text { Q7-Ajuda a organizar um novo serviço na } \\
\text { comunidade }\end{array}$ & 0,733 & 0,803 & 1,815 & & \\
\hline \multirow{2}{*}{7} & \multirow{2}{*}{$\begin{array}{l}\text { Tolerância à } \\
\text { Diversidade }\end{array}$} & Q28-Acredita que o multiculturalismo é saudável & 0,758 & 0,828 & 3,565 & \multirow{2}{*}{3,523} & \multirow{2}{*}{0,766} \\
\hline & & Q29-Aprecia diferentes estilos de vida & 0,743 & 0,778 & 3,481 & & \\
\hline & \multirow{2}{*}{$\begin{array}{l}\text { Atividades em } \\
\text { um contexto } \\
\text { social }\end{array}$} & Q9-Sai da comunidade local para visitar a família & 0,653 & 0,793 & 3,500 & \multirow[b]{2}{*}{3,491} & \multirow[b]{2}{*}{0,500} \\
\hline & & $\begin{array}{l}\text { Q10-Tem acesso à informação para tomar } \\
\text { decisões importantes }\end{array}$ & 0,697 & 0,782 & 3,481 & & \\
\hline
\end{tabular}

Fonte: Compilação dos dados da pesquisa realizada

O terceiro fator deste estudo, "Sentimento de Confiança e Segurança", apresentou similaridade com o apresentado por Onyx e Bullen (2000), tendo apenas incorporado a variável Q23 ("Quando você sai para fazer compras no seu bairro, ou comunidade, você se sente entre amigos, entre conhecidos?") que era originalmente de outro fator. Este fator retrata a confiança, um indicador extremamente importante para o capital social, pois, ao se confiar, logo se compartilham valores e sentimentos, aumentando a intensidade das trocas e dos relacionamentos.

Segundo Putnam (1996) e Fukuyama (1996), a confiança é a condição primeira para que haja cooperação e trabalho conjunto, e mesmo havendo objetivos comuns entre as pessoas, somente com a existência de confiança é possível ocorrer cooperação. Para este estudo, o fator apresentou uma média geral $(2,397)$ indicando um nível significativo desta faceta do capital social no grupo de consumidores da feira virtual.

Os demais fatores deste estudo - quarto "Vínculos com a vizinhança", quinto "Proatividade no contexto de trabalho", sexto "Envolvimento em projetos comunitários", sétimo "Tolerância à Diversidade" e oitavo "Proatividade em um contexto social" - também apresentaram médias significativas, todas acima de 2,000, mas, como a variância explicada dos dados foi relativamente baixa, não foram tão relevantes no contexto deste estudo.

Destaca-se que as variáveis que compõem o quinto, sétimo e oitavo fatores apresentaram as médias mais altas, demonstrando que estas dimensões do capital social estão bastante presentes no projeto analisado, fortalecendo entre os integrantes do GCR Bem da Terra conexões com pessoas desconhecidas, de diferentes origens e estilos de vida, desenvolvendo laços horizontais de amizade nas atividades desenvolvidas no contexto social. Por outro lado, de forma similar ao que encontraram Macke et al. (2008) na comunidade de Farroupilha, também no Rio Grande do Sul, as variáveis associadas ao vínculo com a vizinhança e com a participação no ambiente comunitário local apresentaram os menores índices na avaliação do capital social. Desta forma, predomina no grupo que compõe o GCR Bem da Terra um capital social que se vincula com a busca do "bem comum" e não com a vizinhança ou com os moradores de um mesmo bairro, mas vínculos com pessoas do mesmo ambiente de trabalho que se identificam com as mesmas bandeiras políticoideológicas e que vislumbram um contexto social mais proativo. De certa forma, estes resultados refletem aquilo que na literatura é conhecido como capital social de ponte 
(bridging social capital), o qual possibilita a ação coletiva, uma vez que favorece os vínculos com membros oriundos de grupos, empresas e sindicatos distintos, exatamente como é o caso dos do GCR Bem da Terra.

Em relação ao capital social entre os membros ativos e inativos da feira, percebe-se que os consumidores ativos apresentaram maiores médias em seis dos oito fatores (Tabela 5). Apenas nos fatores "Envolvimento comunitário" e "Proatividade no contexto social" as médias dos consumidores ativos não foram superiores ao dos inativos.

Destaca-se que a diferença entre consumidores ativos e inativos apresentou-se estatisticamente significativa para os três primeiros fatores, sendo estes o "Sentimento de segurança e confiança" e a "Participação da Comunidade Local", e em nível de $10 \%$ de probabilidade o fator "Identificação social e satisfação pela vida".

Corroborando com a análise apresentada na (Tabela 5), acrescenta-se a expressão verbal de dois consumidores inativos que refletem os interesses particulares deste grupo de consumidores. As falas são coerentes com os resultados quantitativos deste estudo ao apontarem que os inativos são mais motivados pela perspectiva utilitária, seja do consumo do alimento orgânico ou dos benefícios auferidos na participação em um projeto social.

[...] inicialmente eu fui a, como se chama o nome da pessoa responsável? articuladora, durante um ano. Procurava comprar semanalmente... aconteceu a questão da qualidade dos produtos, principalmente dos hortifrutis, às vezes eu comprava uma coisa e era outra, às vezes eu chegava lá e não tinha quantidade... (Consumidor inativo A, 2019).

E o segundo acrescenta:
[...] com relação aos produtos, não tinha problema muito com relação à perecibilidade deles, ou a cara do produto né, vamos dizer assim, né... Algo que eu vinha como um déficit era da oferta de produtos em geral, não tinha frutas, né. Tinha alguns produtos que [...] é comum a gente consumir na semana, numa sexta básica que também não tinham assim, na época, e aí a gente tinha que fazer uma parte das compras semanais, vamos dizer assim, na Feira e outra parte no mercado tradicional (Consumidor inativo B, 2019).

Os inativos são mais preocupados com questões práticas. Se aspectos forem deixando de existir, como a pronta oferta, a qualidade aparente, entre outros, isso faz com que as motivações para permanecer no grupo se enfraqueçam. Assim, a permanência no grupo passa a não mais fazer sentido, visto que elementos importantes ficam esvaziados.

Diante destes fatos, pode-se concluir que os elementos do capital social, principalmente a socialização entre os membros durante o recebimento, separação e entrega dos produtos oriundos dos agricultores familiares era instrumental no processo de criação de capital social. Se, como mostrado na introdução, a feira virtual está enfrentando dificuldades de manutenção de um número viável de consumidores, o capital social, ou melhor, a falta dele parece fazer a diferença entre os membros inativos. Confiança, reciprocidade, responsabilidade social conferem significado e sentido para se abrir mão do tempo individual em prol de trabalho voluntário e, no momento em que estes elementos não estão mais presentes, permanece apenas a relação de consumo, que pode ser realizada em qualquer outro espaço mercadológico que não um projeto de economia solidária.

TABELA 5 - Teste $t$ de student entre médias dos fatores para consumidores ativos e inativos

\begin{tabular}{ccccc}
\hline \multirow{2}{*}{ Fatores } & \multicolumn{2}{c}{ Escores médios } & \multirow{2}{*}{ Teste t } & P-valor \\
\cline { 2 - 3 } & Ativos & Inativos & & 0,075 \\
Identificação Social e Satisfação pela vida & 0,1047028 & $-0,1873628$ & 1,450 & 0,022 \\
Participação na Comunidade Local & 0,1458202 & $-0,2609414$ & 2,038 & 0,022 \\
Sentimentos de Confiança e Segurança & 0,2372071 & $-0,4244759$ & 3,430 & 0,000 \\
Vínculos com a Vizinhança & 0,0206471 & $-0,0369474$ & 0,283 & 0,389 \\
Proatividade no Contexto de Trabalho & 0,0707419 & $-0,265908$ & 0,974 & 0,166 \\
Envolvimento comunitário & $-0,288880$ & 0,0516942 & $-0,396$ & 0,346 \\
Tolerância à Diversidade & 0,0270076 & $-0,0483293$ & 0,370 & 0,356 \\
Proatividade no Contexto Social & $-0,0669659$ & 0,1198337 & $-0,922$ & 0,179 \\
\hline
\end{tabular}

Fonte: Elaborado pelo Autor 


\section{CONCLUSÕES}

A interação social na Rede Bem da Terra, conforme mostra o estudo, ocorre pelas afinidades comuns, pelos valores e pelas normas partilhadas através de vínculos de amizade e de trabalho. Trata-se de um grupo aberto a diferentes culturas e estilos de vida, com um bom nível de confiança entre os membros, o que representa um bom indicador para facilitar a cooperação no grupo.

O capital social existente no GCR da rede Bem da Terra apresenta níveis que garante o bom funcionamento da Feira Virtual. Se nem todas as dimensões ou facetas do capital social estão presentes em níveis altos, há farta evidência que aquelas dimensões importantes para o pleno funcionamento da rede estão presentes. É possível também que nem todas as dimensões do capital social, conforme preza a literatura, sejam fundamentais para o funcionamento da GCR da rede Bem da Terra.

Como elementos importantes encontrados no contexto da pesquisa, salienta-se a forte identificação social e a confiança, sendo o que confere consistência ao grupo e permite a busca de soluções conjuntas, possibilitando que eles encontrem estratégias para garantir a permanência da Feira Virtual. A confiança, a qual foi construída entre pessoas de origens culturais diferentes e reforçado ao longo do tempo, é essencial para possibilitar a cooperação do grupo.

$\mathrm{O}$ fato de os consumidores inativos terem menos capital social demonstra que, mesmo eles tendo ingressado de forma voluntária por meio da acolhida e, portanto, conscientes da conduta que seria demandada, eles diferem dos consumidores ativos, sendo a diferença significativa nas dimensões do capital social "Sentimentos de Segurança e Confiança", "Participação Comunitária" e "Identificação Social". As consequências desta diferença podem estar impactando na permanência destes respondentes na feira, os quais, ao apresentarem menores níveis destas dimensões do capital social, podem ser menos identificados e motivados com a proposta da economia solidária e, portanto, não estão dispostos a assumir a responsabilidade e o compromisso da participação.

Salienta-se, contudo, que embora o estudo tenha trazido uma importante contribuição por relacionar o capital social com as iniciativas de consumidores dentro da perspectiva da economia solidária, o estudo carece ainda de aprofundamentos. Primeiramente, futuras pesquisas poderão analisar o capital social em projetos de economia solidária utilizando-se de outros instrumentos analíticos. Neste sentido, uma sugestão é seguir o quadro referencial proposto por Nahapiet e
Ghoshal (1998), os quais entendem o capital social nas dimensões estrutural, relacional e cognitiva. Certamente, projetos de economia solidária trazem em seu bojo padrões de conexões e laços entre seus membros (dimensão estrutural); uma dimensão comportamental da relação, que se refere à confiança e às normas, obrigações e expectativas das relações entre membros (dimensão relacional); e a perspectiva simbólica que dá significado e comprometimento (dimensão cognitiva). Finalmente, futuras pesquisas poderão beneficiar-se ao considerar estas dimensões correlacionadas, propondo modelos analíticas não ortogonais.

\section{AGRADECIMENTO}

Agradecimento à Coordenação de Aperfeiçoamento de Pessoal de Nível Superior (CAPES).

\section{REFERÊNCIAS}

MARTÍN-ALCÁZAR, F.; RUIZ-MARTÍNEZ, M.; SÁNCHEZ-GARDEY, G. Assessing social capital in academic research teams: a measurement instrument proposal. Scientometrics, v. 121, n. 2, p. 917-935, 2019.

BALTHAZAR, U. C.; CARDOSO, V. S. A isenção de ICMS incidente sobre a saída de bens e produtos nos empreendimentos econômicos solidários como fator de desenvolvimento econômico e social. Revista de Direito, v. 8, n. 02, p. 217-238, 2016.

HADOR, B. B. How intra-organizational social capital influences employee performance. Journal of Management Development, v.35, n.09, p.1119-1133, 2016.

BOURDIEU, P. Le capital social: notes provisoires. Actes de la recherche en sciences sociales, v. 31, n. 1, p. 2-3, 1980.

BOURDIEU, P. The forms of capital. Handbook of theory and research for the sociology of education. In: Richardson, J. (Ed.). Handbook of theory and research for the sociology of education. New York: Greenwood, v. 241, n. 258, p. 19, 1986.

CALABRO, G. Criando um grupo de consumo responsável: um passo a passo para começar a estabelecer um GCR. Piracicaba: Instituto Terra Mater, 2016. 
CASCIARO, T.; LOBO, M. S. Affective primacy in intraorganizational task networks. Organization Science, v. 26, n. 2, p. 373-389, 2015.

CHEN, M. H.; CHANG, Y. C.; HUNG, S. C. Social capital and creativity in $R \& D$ project teams. R\&d Management, v. 38, n. 1, p. 21-34, 2008.

COLEMAN, J. S. Social capital in the creation of human capital. American Journal of Sociology, v. 94, p. S95-S120, 1988.

CRUZ, A. Os 'grupos de consumo responsável' no Brasil? experiências inovadoras de comercialização solidária. In: X Seminario Académico Internacional PROCOAS AUGM, 2014, Mendoza. Anais do X Seminario Académico Internacional PROCOAS AUGM, Mendoza: Marcos Mattar Ediciones, 2014, p. 203-215.

FIELD, A. Descobrindo a estatística usando o SPSS. Porto Alegre: Artmed, 2009.

FONTANELLA, B. J. B. et al. Amostragem em pesquisas qualitativas: proposta de procedimentos para constatar saturação teórica. Cadernos de Saúde Pública, v. 27, p. 388-394, 2011.

FONTI, F.; MAORET, M. The direct and indirect effects of core and peripheral social capital on organizational performance. Strategic Management Journal, v. 37, n. 8, p. 1765-1786, 2016.

FORMIGA, N. S.; OLIVEIRA FREIRE, B. G.; FERNANDES, A. Evidência de construto, invariância fatorial e validade convergente da escala de capital social organizacional em trabalhadores brasileiros. Eureka, v. 16, n. 01, p. 34-59, 2019.

FUKUYAMA, F. Confiança: as virtudes sociais e criação da prosperidade. Rocco, 1996.

FUKUYAMA, F. A grande ruptura: A natureza humana e a reconstituição da ordem social. Rio de Janeiro: Rocco, 2000 .

GAIGER, L. I. G.; GRUPO ECOSOL. A economia solidária no Brasil: uma análise de dados nacionais. São Leopoldo: Oikos, 2014
HAESBAERT, R. Da desterritorialização à multiterritorialidade. Boletim Gaúcho de Geografia, v. 29, n. 1, 2003.

HAESBAERT, R. Dos múltiplos territórios à multiterritorialidade. 2004. Porto Alegre. Disponível em: http://default/files/CONFERENCE_Rogério_ HAESBAERT.pdf.

HAIR, J. F. et al. Análise Multivariada dos dados. Porto Alegre: Bookman, 2009.

HAU, Y. S. et al. The effects of individual motivations and social capital on employees' tacit and explicit knowledge sharing intentions. International Journal of Information Management, v. 33, n. 2, p. 356-366, 2013.

HU, L.; RANDEL, A. E. Knowledge sharing in teams: Social capital, extrinsic incentives, and team innovation.

Group \& Organization Management, v. 39, n. 2, p. 213-243, 2014.

IPEA. Os novos dados do mapeamento de economia solidária no Brasil: nota metodológica e análise das dimensões socioestruturais dos empreendimentos. 2016. Disponível em: <http://repositorio.ipea.gov. $\mathrm{br} /$ bitstream/11058/7410/1/RP_Os\%20Novos\%20 dados $\% 20$ do $\% 20$ mapeamento $\% 20$ de $\% 20$ economia $\% 20$ solid\%C3\%A1ria\%20no\%20Brasil_2016.pdf.>. Acesso em: 02 jun. 2019.

IPEA. Mercado de Trabalho conjuntura e análise. S. d. Disponível em: <http://www. ipea.gov.br/portal/index.php?option=com content\&view $=$ article $\& i d=34732 \&$ Itemid $=9>$. Acesso em: 02 jun. 2019.

MACKE, J.; SARATE, J.A. R.; DAMACENA, C. Avaliação do capital social em uma cidade gaúcha: a percepção dos estudantes de administração. Revista Eletrônica de Administração, v. 16, n. 3, p. 611-635, 2010.

MAIA, M. Economia solidária e o microcrédito no Brasil: avanços ou insuficiências? Revista de Administração de Roraima, v. 4, n. 1, p. 119-133, 2014.

MALHOTRA, N. K. Pesquisa de marketing: uma orientação aplicada. (4. ed.) Porto Alegre: Bookman, 2001. 
MOHAMMADI, M. R. et al. Application of Different Techniques of Factor Analysis to Develop Neighborhood Social Capital Rating Scale. Social Indicators Research, v. 150, p.n375-391, 2020.

NAHAPIET, J.; GHOSHAL, S. Social capital, intellectual capital, and the organizational advantage. Academy of Management Review, v. 23, n. 2, p. 242-266, 1998.

NESIC UCPEL. (s.d.). Disponível em: <http://antares. ucpel.tche.br/nesic/quemsomos.php $>$. Acesso em: 10 mai. 2019.

ONYX, J.; BULLEN, P. Measuring social capital in five communities. The Journal of Applied Behavioral Science, v. 36, n. 1, p. 23-42, 2000.

PORTES, A. Social capital: Its origins and applications in modern sociology. Annual Review of Sociology, v. 24, n. 1, p. 1-24, 1998.

OLIVEIRA, A. A. R. O movimento de economia solidária: essencialidades do princípio educativo. Revista Iberoamericana de Educación, v. 76, p. 187-208, 2018.

PUTNAM, R. D. Comunidade e Democracia: a experiência da Itália Moderna. trad. Luiz Alberto Monjardim. Rio de Janeiro: Ed. Fundação Getúlio Vargas, 1996.

PUTNAM, R. D. et al. Bowling alone: The collapse and revival of American community. Simon and Schuster, 2000.

RIBEIRO, K. Á.; OLIVIERA, L. H. F. S. Entraves e Desafios a Sustentabilidade dos Empreendimentos Solidários na Região do Submédio São Francisco. Revista Brasileira de Assuntos Regionais e Urbanos, v. 3, n. 1, p. 106-119, 2017.

SANTOS, L. M. L.; VIEIRA, S. F. A.; BORINELLI, B. Economia solidária e estratégia: entre princípios e pragmatismo. Revista Ibero Americana de Estratégia, v. 12, n. 4, p. 261-278, 2013.
SANTOS, L. M. L.; VIEIRA, S. F. A.; BORINELLI, B. Economia solidária e estratégia: entre princípios e pragmatismo. Revista Ibero Americana de Estratégia, v. 12, n. 4, p. 261-278, 2013.

SILVA, M. K.; OLIVEIRA, G. de L. Solidariedade assimétrica: capital social, hierarquia e êxito em um empreendimento de" economia solidária". Revista Katálysis, v. 12, n. 1, p. 59-67, 2009.

SILVA, R. A; OLIVEIRA, V. M; CORREIA, S. É. N. Impactos da participação de mulheres em iniciativas de economia solidária no Cariri Paraibano. Race: Revista de Administração, Contabilidade e Economia, v. 17, n. 3, p. 851-866, 2018.

SOUTO, E. P. et al. Validade da estrutura fatorial da escala de capital social utilizada na linha de base no ELSA-Brasil. Cadernos de Saúde Pública, v. 32, p. e00101515, 2016.

VALENZUELA, C; MARTÍNEZ, M. L.; CUMSILLE, P. Validation of the factorial structure of social capital in youth involved in prosocial and political organizations. Youth \& Society, v. 52, n. 8, p. 1359-1376, 2020.

XIAO, Z; TSUI, A. S. When brokers may not work: The cultural contingency of social capital in Chinese high-tech firms. Administrative Science Quarterly, v. 52, n. 1, p. 1-31, 2007.

YEN, Y-F; TSENG, J-F; WANG, H-K. The effect of internal social capital on knowledge sharing. Knowledge Management Research \& Practice, v. 13, n. 2, p. 214$224,2015$.

YIN, R. K. Estudo de caso: planejamento e métodos. (5. ed.). Porto Alegre: Bookman, 2010.

YIU, D. W.; LAU, C-M. Corporate entrepreneurship as resource capital configuration in emerging market firms. Entrepreneurship Theory and Practice, v. 32, n. 1, p. 37-57, 2008. 